\title{
INFLUENCE OF TIME ON THE BEARING CAPACITY OF PRECAST PILES
}

\author{
KAZIMIERZ GWIZDAŁA, PAWEe WiĘCŁAWSKI \\ Gdańsk University of Technology, \\ Department of Geotechnics, Geology and Maritime Engineering, Gdańsk, Poland, \\ e-mail:kgwiz@pg.gda.pl,pawwiecl@pg.gda.pl
}

\begin{abstract}
One of the most popular types of foundations in layered subsoil with very differentiated soil shear strengths are precast piles. One of the reasons is the fact that we can well control the driving process during the installation of these piles. The principles of the assessment of bearing capacity and settlements of the piles given by Eurocode 7, concentrate on two main methods, i.e., Static Pile Load Tests (SPLT) and Dynamic Driving Analysis (PDA). However, the evaluation of real load-settlement curve for piles being driven in layered subsoil, where noncohesive and cohesive soils occur alternately, is neither easy nor straightforward. In the paper, the results of both SPLT and PDA tests for objects on the highways in Poland are presented. Field investigations carried out at various time points since the installation of piles (from 7 to 90 days) revealed an increase of bearing capacity with time. The reason for this may be a change of the soil state near the piles due to their driving (displacement of piles) as well as a change of microstructure at the contact between soil and pile shaft. The results of load tests were referred to the geotechnical parameters of the subsoil, which was recognized by means of traditional borings and CPTU tests. The results of tests allow phenomena occurring with time to be assessed and bearing capacity of precast piles to be predicted.
\end{abstract}

\section{INTRODUCTION}

Foundation of any of the engineering structures is currently often facing the problem of complex geotechnical conditions. It is often found that in the subsoil designated for foundation of new objects one can meet weak soils with low shear strength and high compressibility, below which are soils with much higher bearing capacity (medium dense or dense sands or cohesive soils).

Technically and economically justified design regarding complex soil conditions should fully incorporate natural, in situ geotechnical parameters.

The ideal of design and installation of piles should lead to the improvement of transmission of loads into the subsoil. One of the factors that is frequently neglected is the influence of time on the bearing capacity of deep foundations. The analysis of this problem can be found elsewhere (Gwizdała [2], Cichy et al. [4], Kumor and Szpakowski [5], Zadroga [6], Skov and Svinkin [8]).

In the paper, the investigation results of the time-dependence of bearing capacity of piles in layered subsoil consisting of weak and strong soils are presented. The investigations were based on static (SPLT) and dynamic (PDA) load tests. 


\section{INFLUENCE OF TIME ON BEARING CAPACITY OF PILE FOUNDATION}

One of the design methods proposed in Eurocode 7, is observational method. In Poland, the method is usually applied to long, continuous structures. Observational method was used, for example, in designing the quay in Gdynia, trestle bridge in Gdańsk, and a bridge in Kwidzyń. The main advantage of the observational method is the possibility of modifying original construction solutions during its foundation, based on the analyses of the response of already existing sectors. This method was also applied to deep foundations based on the observed increase of bearing capacity of piles with time as compared to initial values.

This observation contributed to the optimal design of driven precast reinforced concrete piles. The assessment of pile bearing capacities changes with time was based on static and dynamic load tests. Some comparative examples are presented in Figs. 1-10.

First columns in Figs. 1, 2, 5 and 9 correspond to calculated bearing capacity $N_{t}$ including negative friction acting over the pile shaft. Bearing capacities were calculated based on analytical solutions, according to (Gwizdała [2, [3) and PN-83/B-02482. Subsequent columns presented in the diagrams correspond to bearing capacities of piles after some period of time. These values were determined based on static and dynamic load tests.

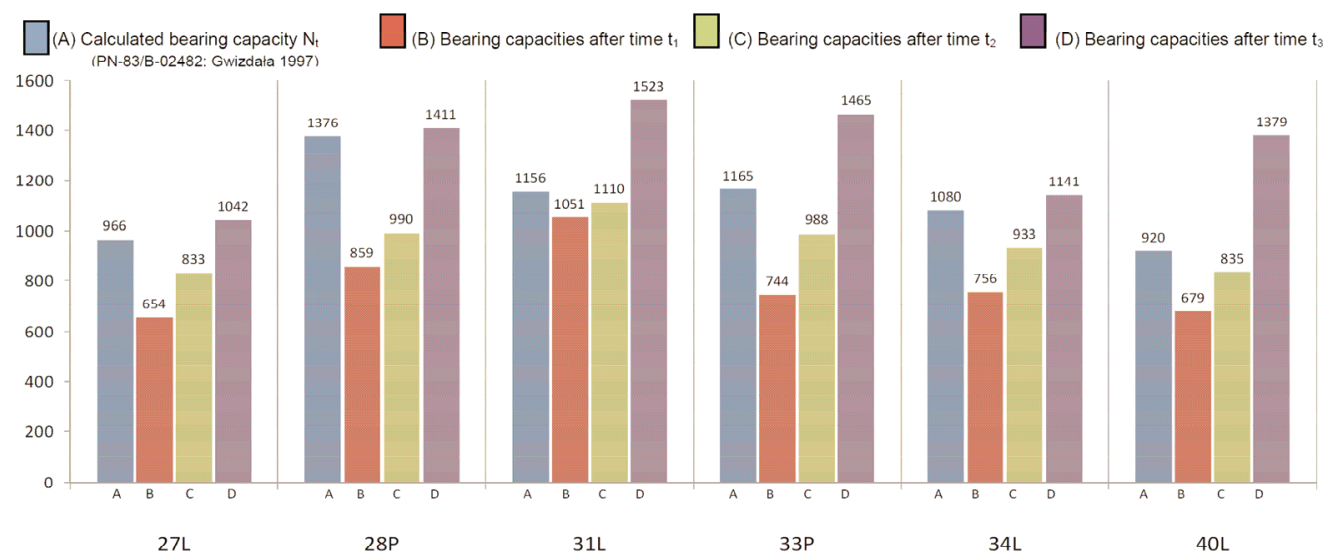

Fig. 1. Increase of bearing capacities with time for precast pile

For the majority of piles their bearing capacities were higher than designed values. For part of supports there is some bearing capacity margin. The increase of bearing capacity with time can be predicted according to the following relationship, (Gwizdała [2], Skov and Svinkin [8]): 


$$
Q_{t}=Q_{0}\left(1+A \cdot \log \frac{t}{t_{0}}\right)
$$

where:

$Q_{t}-$ bearing capacity of pile after time $t$,

$Q_{0}-$ bearing capacity of pile after time $t_{0}$,

$t_{0} \quad-$ time given in the form of an empirical coefficient, for sands $t_{0}=0.5$, for cohesive soils $t_{0}=1.0$,

$A \quad$ - empirical coefficient, for sands $A=0.2$, for cohesive soils $A=0.6$.

Due to empirical origin of the above relationship it should be applied rather carefully since the process of bearing capacity change in various soil conditions can run in different ways.

\subsection{NON-COHESIVE SOIL}

Soil conditions were determined based on standard geotechnical investigations and CPTs. The structures were classified to the second geotechnical category.

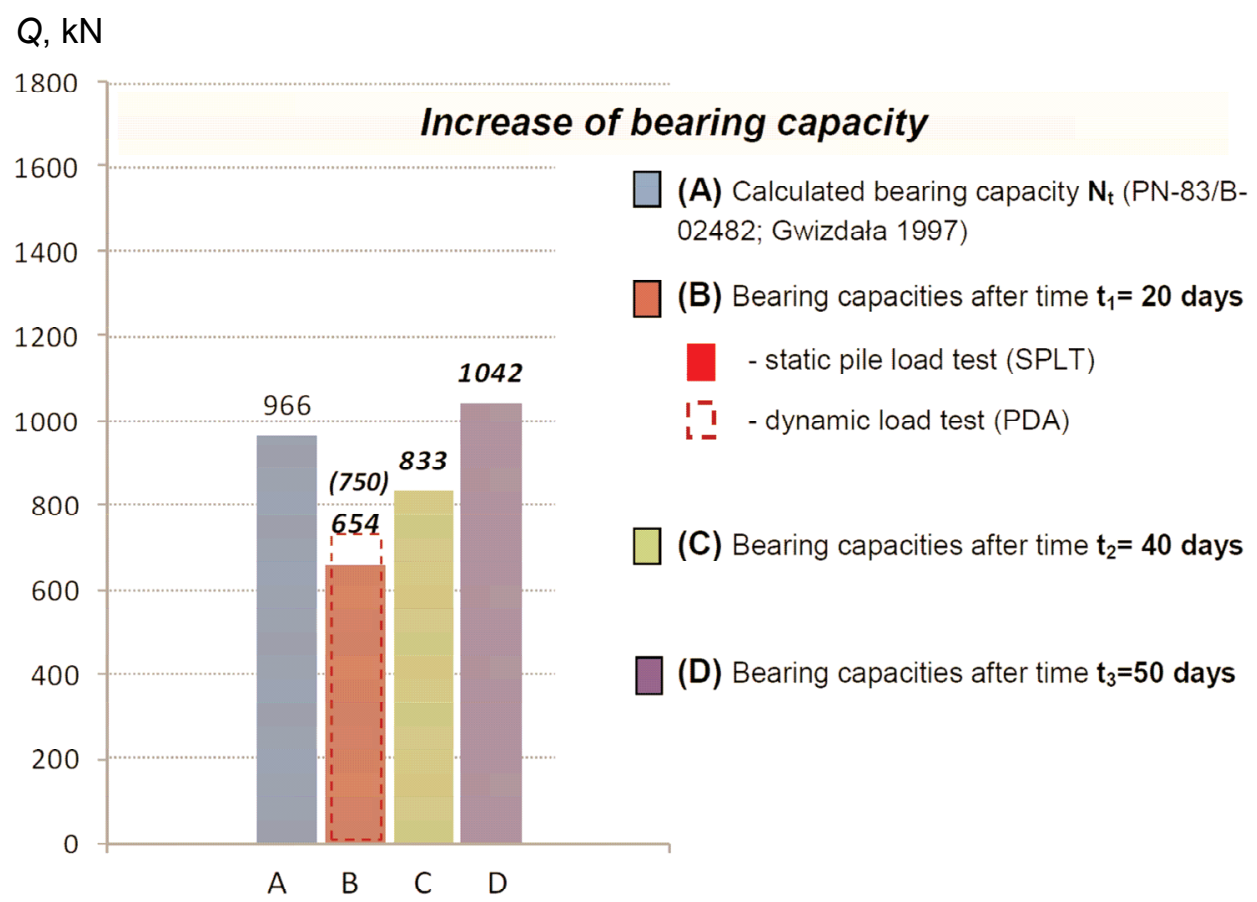

Fig. 2. Increase of bearing capacity for pile in support No. 27L 
Existing soil conditions have excluded shallow foundations. The uppermost layer is built of $0.6 \mathrm{~m}$ thick backfill. Below, organic soils represented by peat and mud can be found. Organic soils with the consistency index $I_{C}=0.50-0.20$ and CPT cone resistance $q_{c}=1-3 \mathrm{MPa}$ occur to the depth of 10-15 $\mathrm{m}$. Underneath, medium dense and dense fine sands are found $\left(I_{D}=0.55-0.72\right.$ and $\left.q_{c}=10-25 \mathrm{MPa}\right)$. The level of water table corresponds to the surface level. Typical geotechnical profile of the site discussed is shown in Fig. 4a.

A comparison of real bearing capacity gain and its increase predicted by equation (1) was presented in Fig. 4b.

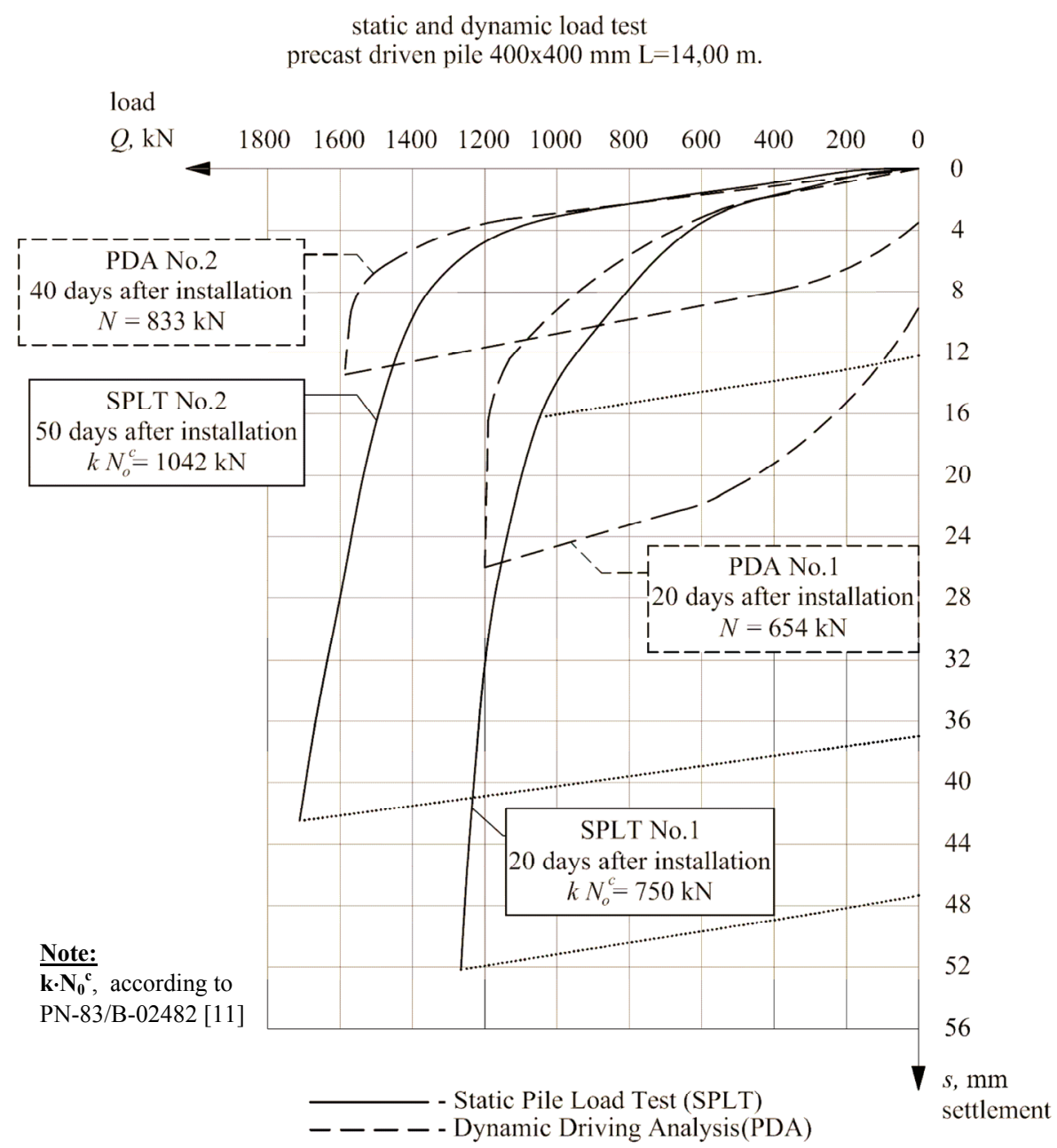

Fig. 3. Q-s curves for pile No. 27L based on static and dynamic load tests 
GEOTECHNICAL PROFILE

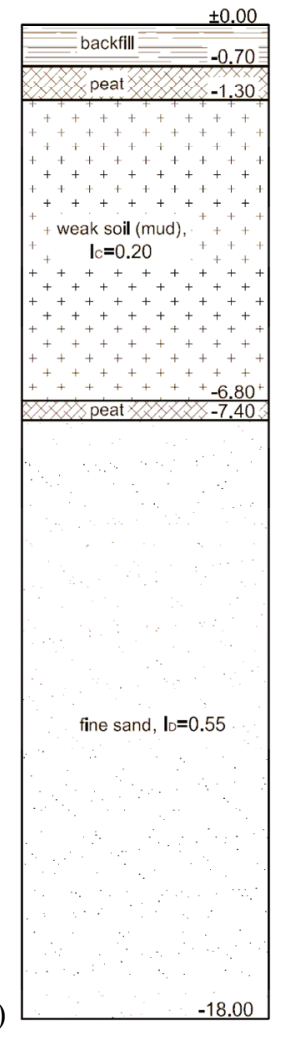

CPT RESULTS

$27 \mathrm{~L}$
CROSS SECTION A-A

600

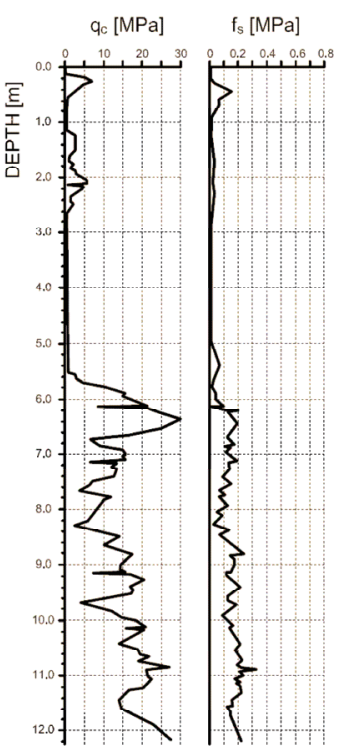

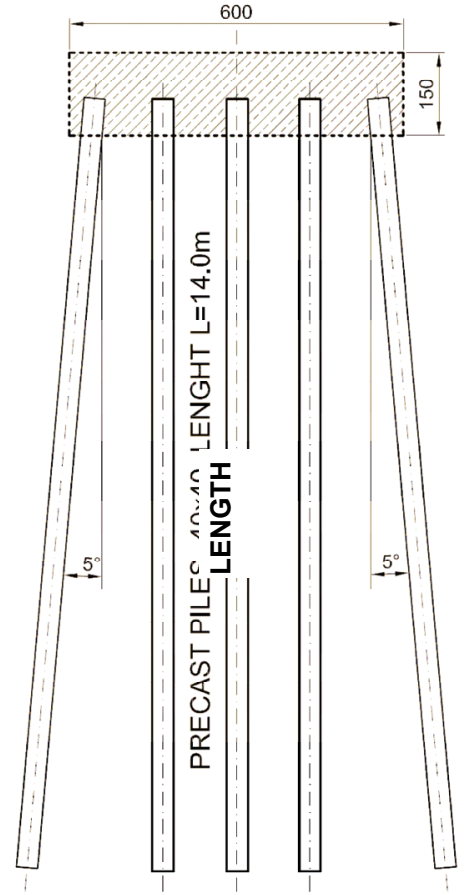

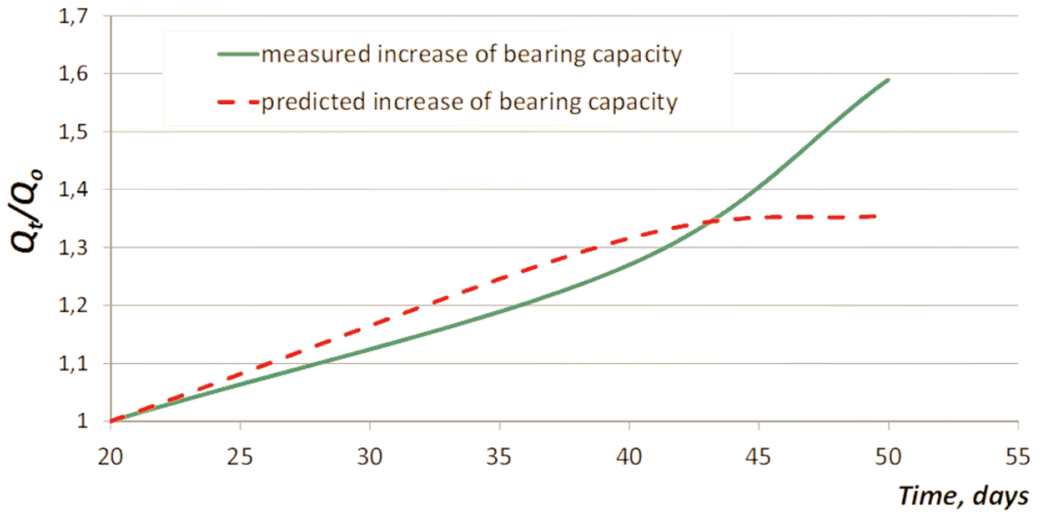

b)

Fig. 4. a) Geotechnical profile (a) and comparison of measured and predicted increase of bearing capacity for pile No. 27L (b) 
$Q, \mathrm{kN}$

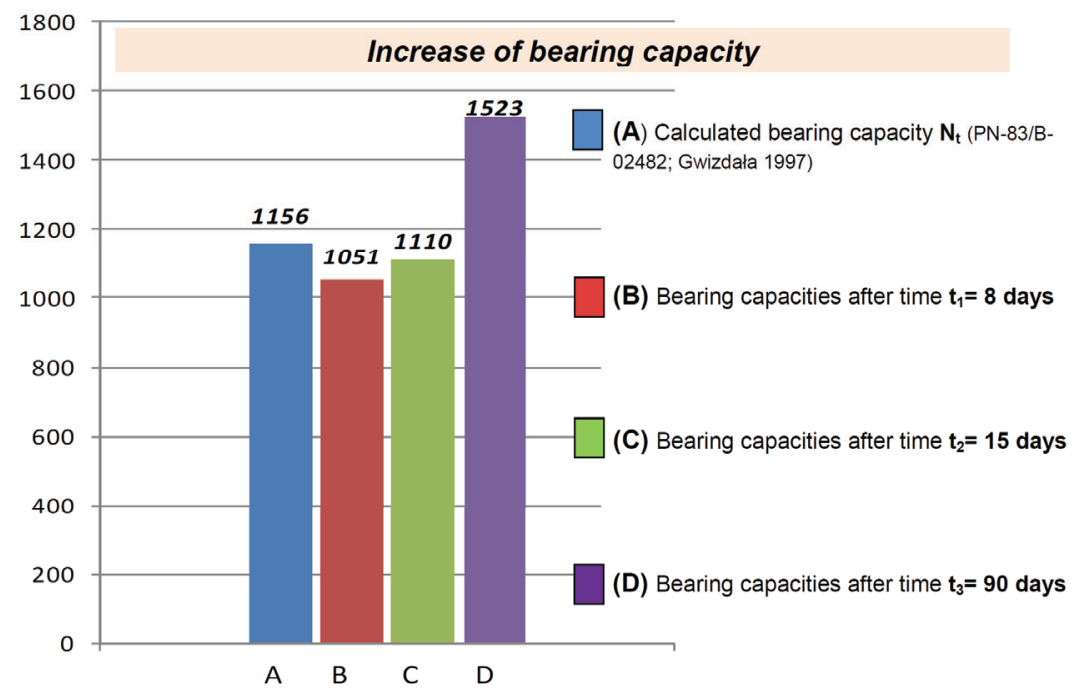

Fig. 5. Increase of bearing capacity with time for pile in support No. 31L

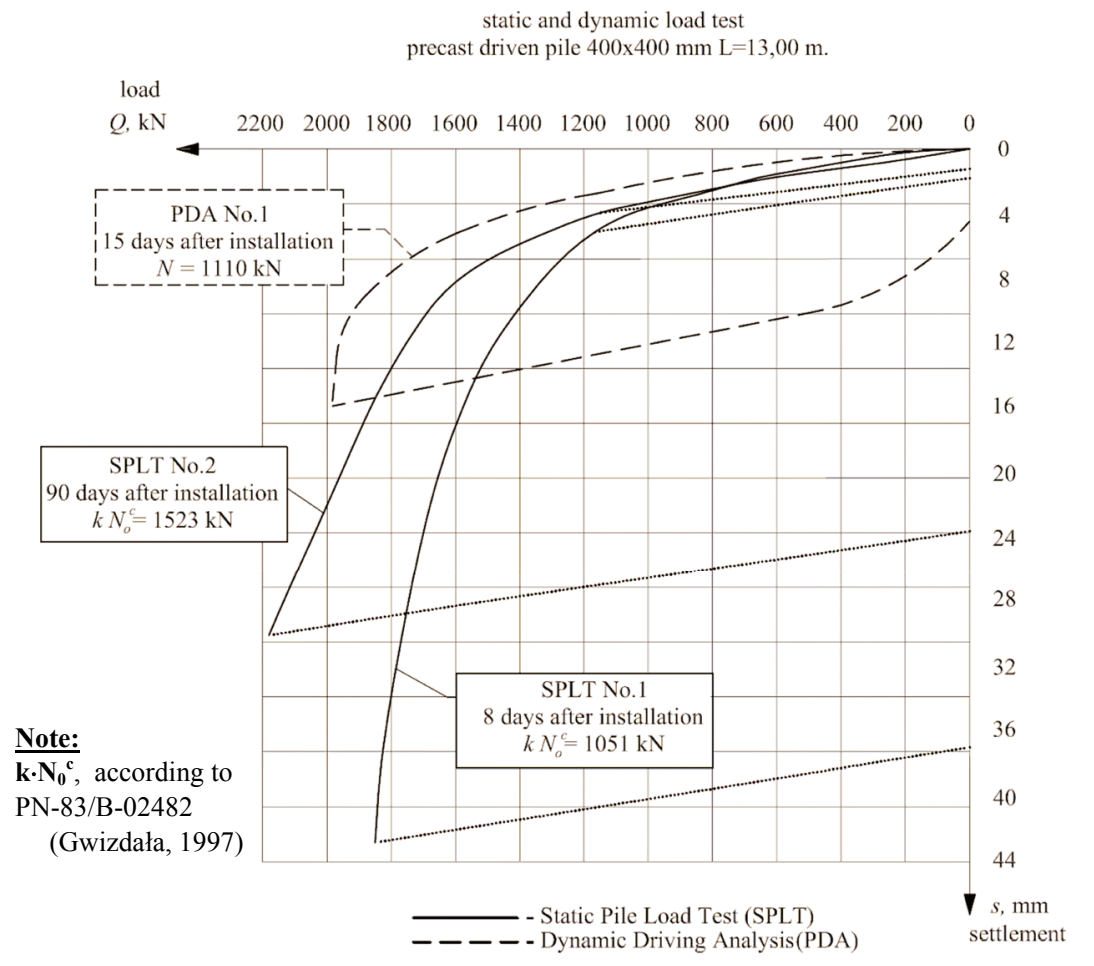

Fig. 6. Q-s curves for pile No. 31L based on static and dynamic load tests 
GEOTECHNICAL PROFILE

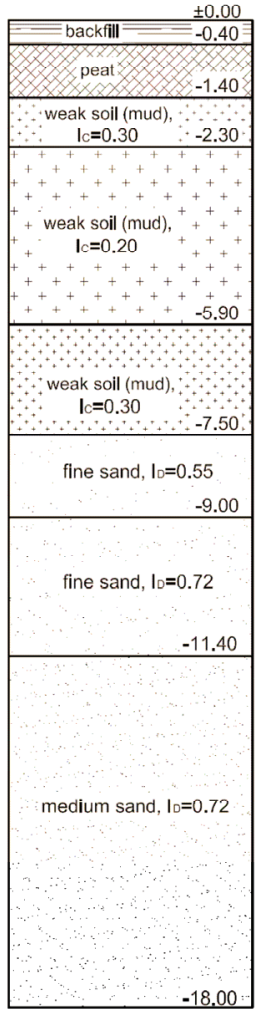

CPT RESULTS

CROSS SECTION A-A

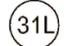

(31L)
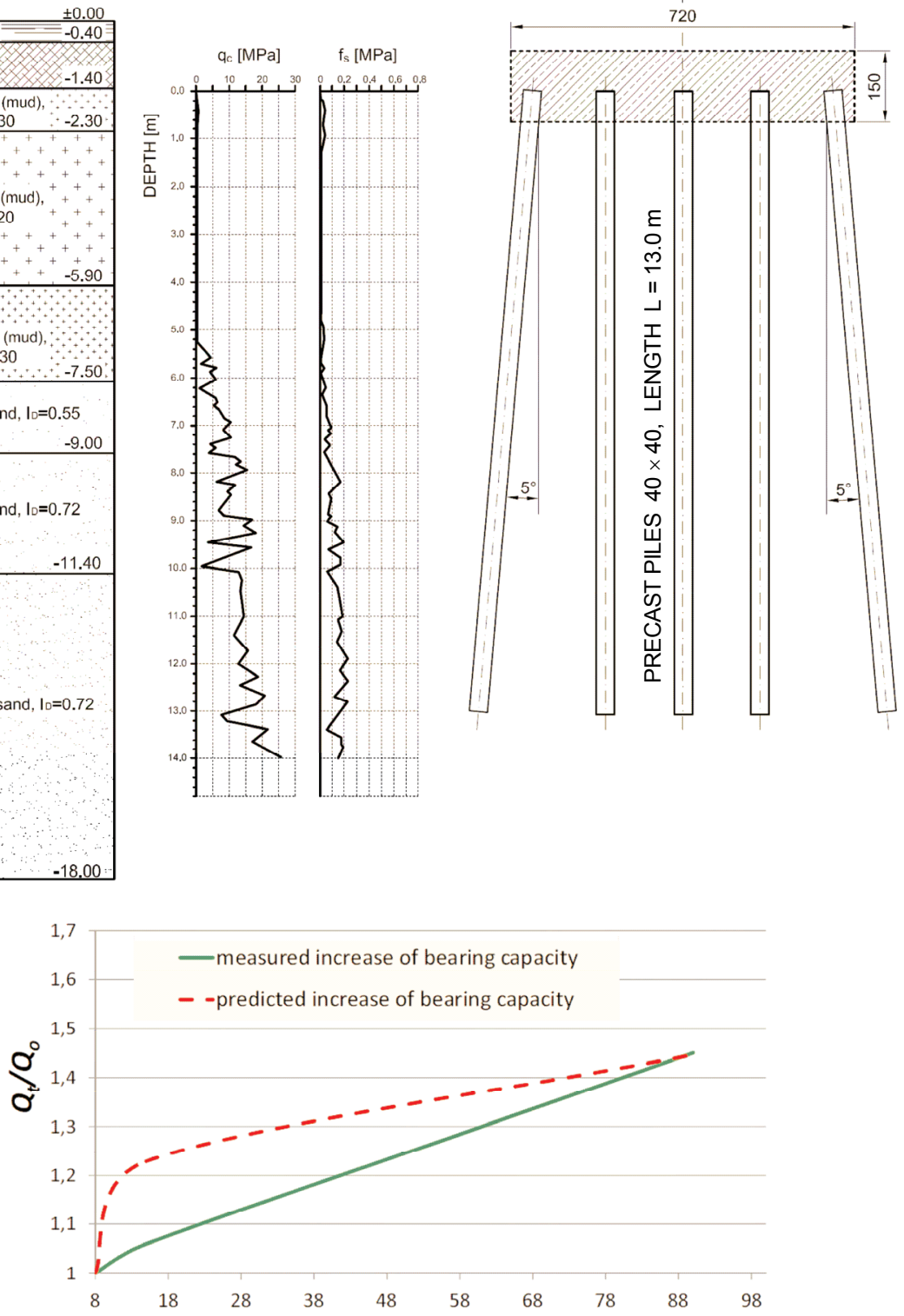

b)

Time, days

Fig. 7. Geotechnical profile (a) and comparison of measured and predicted increase of bearing capacity for pile No. 31L (b) 
For soil conditions analysed average increase of bearing capacity with time was estimated at $60 \%$, after 45 days, on average. For the whole construction, the gain varied from $20 \%$ to $85 \%$. Breaks caused by load tests lasted from 7 to 85 days.

\subsection{COHESIVE SOIL}

Geological structure of a subsoil for another object is also complex. The surface layer consists of construction backfill $3.7 \mathrm{~m}$ thick. The upper backfill layer is built of sand, whereas lower one of clay. The backfill is founded on organic soils, i.e., peat, mud and gyttja. The thickness of this layer varies from 3 to $8 \mathrm{~m}$. Below organic soils, sandy clays and clayey sands of low to high plasticity were found. For the pile analysed consistency index $I_{C}=0.75-0.65$. Water table occurs 1 to $2 \mathrm{~m}$ below the surface.

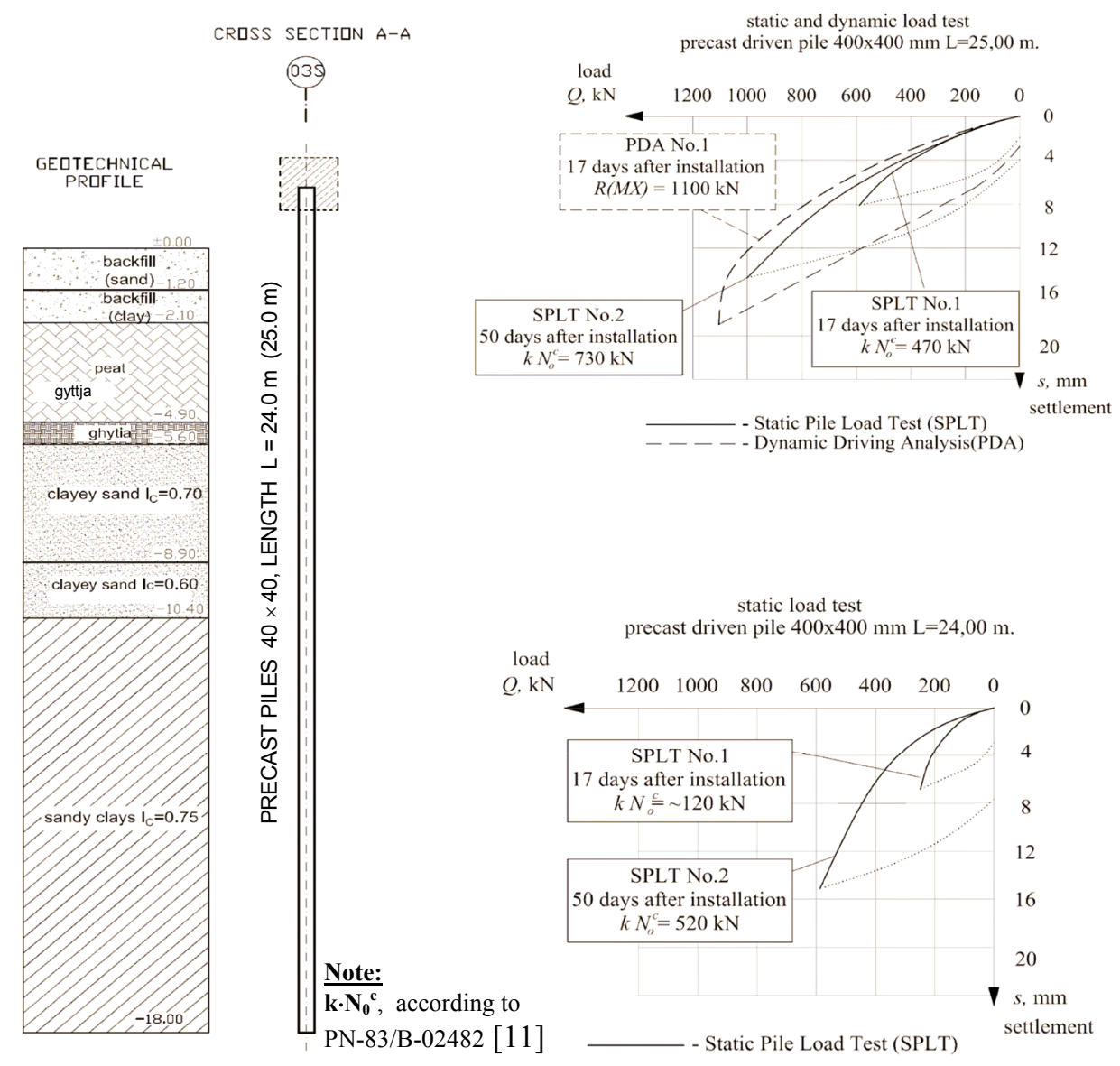

Fig. 8. Geotechnical profile and Q-s curves for pile in $03 \mathrm{~S}$ support, based on static and dynamic tests 
$Q, \mathrm{kN}$

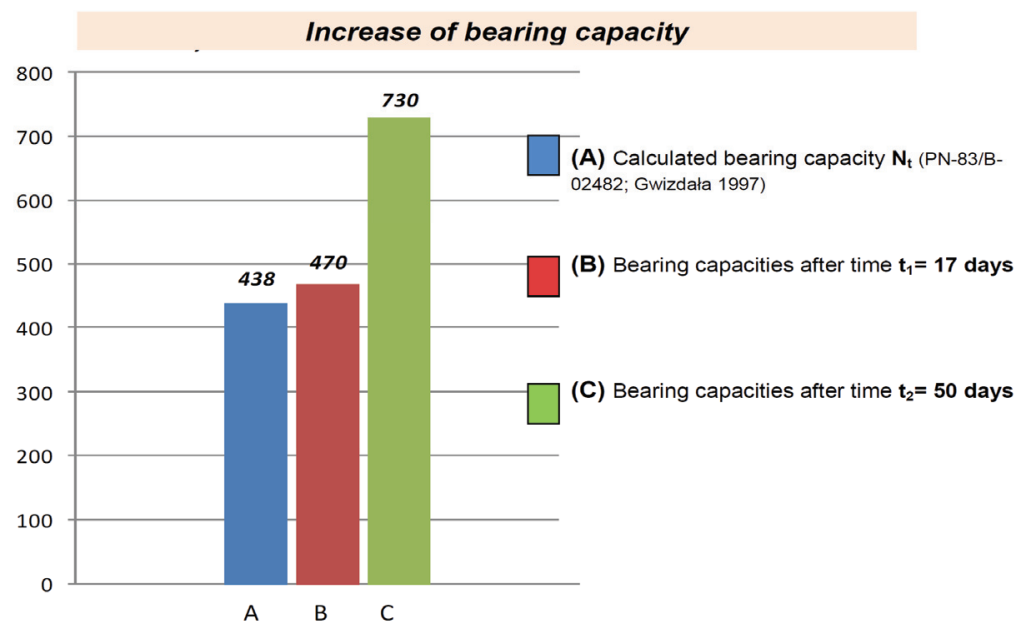

Fig. 9. Increase of bearing capacity with tine for pile in $03 \mathrm{~S}$ support

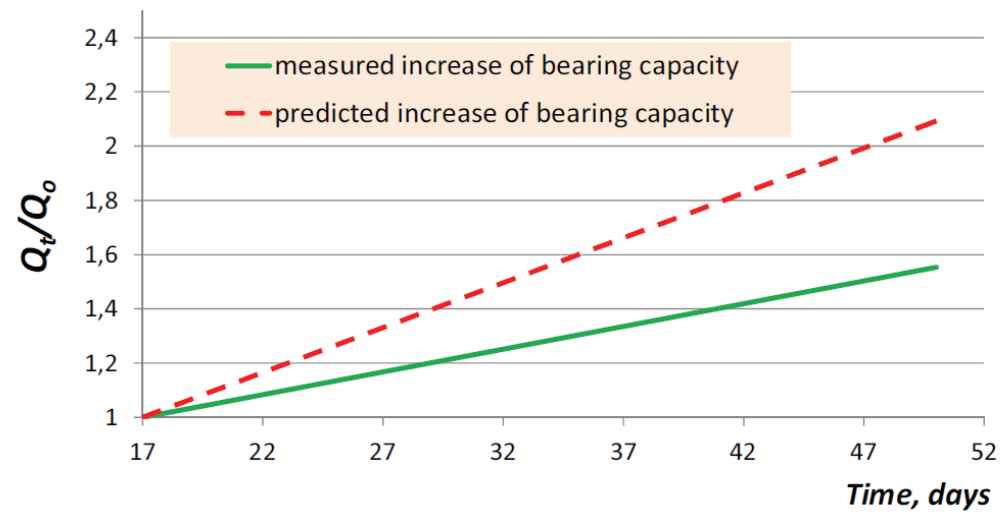

Fig. 10. Comparison of measured and predicted increase of bearing capacity for pile in support $03 \mathrm{~S}$

\section{SUMMARY}

Current technologies of pile installation together with calculation methods allow for rational, economical design with full incorporation of natural geotechnical conditions of the subsoil.

Taking into account the design principles given in Eurocode 7, including observational method, geotechnical engineer should aim at implementation of effective solutions for given geotechnical conditions and designed construction. 
Reliable assessment of bearing capacity should particularly include such soil parameters as pore water pressure, effective vertical and horizontal stresses, coefficient of earth pressure at rest, density of non-cohesive soils and undrained shear strength of cohesive soils. These parameters have significant influence on the increase of bearing capacity of piles with time.

\section{REFERENCES}

[1] GwizdaŁa K., Kowalski J.R., Driven precast piles, (in Polish), PG WILiŚ KG, 2005.

[2] Gwizdala K., Pile foundations. Investigations and application, (in Polish), Vol. 2, PWN, 2013.

[3] Gwizdala K., Polish design methods for single axially loaded piles. Design of Axially Loaded Piles, European Practice, ERTC3 Brussels, Belgium, 17-18 April 1997.

[4] Cichy L., TKaCZYŃSKi G., RYBaK J., Dynamic tests of bearing capacity of precast piles, (in Polish), Inżynieria i Budownictwo, $\mathrm{nr} 3 / 2009$.

[5] KUMOR M.K., SzPAKOWSKI K., The bearing capacity of piles on expansive tertiary clays in the poligone condition, Silesian Technical University, Zeszyty Naukowe, No. 15, 2003.

[6] Zadroga B., Time dependent increase of bearing capacity of piles driven into cohesive soils, Archives of Hydroengineering, No. 3-4/1993.

[7] Skov R., Denver H., Time-dependence of bearing capacity of piles, Proc. 3rd Int. Conf. on Application of Stress-wave Theory to Piles, Ottawa, Canada, 25-27 May 1988.

[8] Skov R., Svinkin M.R., Set-up effect of cohesive soils in pile capacity, Proc. 6th Int. Conf. on Application of Stress-wave Theory to Piles, Sao Paulo, Brazil, 11-13 September 2000.

[9] Sobala D., Driven precast reinforced concrete piles, (in Polish), Aarsleff Sp. z o.o., 2010.

[10] De Cock F., Legrand C., HuYbrechts N., Overview of design methods of axially loaded piles in Europe - Report of ERTC3 - Piles, ISSMGE Subcommittee, XIII-th European Conference of Soil Mechanics and Geotechnical Engineering, Prague, Czech Republic, 25-28 August 2003.

[11] PN-83/B-02482, Bearing capacity of pile and pile foundations.

[12] EN 1997 (2004). Eurocode 7. Geotechnical design.

[13] PN-EN 1997-1:2004, Eurokod 7: Projektowanie geotechniczne - Część 1: Zasady ogólne.

[14] EN 12699:2001, Execution of special geotechnical works. Displacement piles. 